\title{
COVID-19: From Crude Oil to Medical Mask
}

Qinglong Jiang ${ }^{1}$ and Luna $\mathrm{Lu}^{2 *}$

Accepted 21 March $2020 \quad$ DOI: $10.30919 /$ esmm5f766

On March $17^{\text {rd }}, 2020$, cases of COVID-19, a disease caused by coronavirus, were reported to be increased over 1700 in a single day in USA, with 100 reported deaths among total cases about 6500 in all 50 States (Fig. 1a). At the same time, this COVID-19 has spread to almost all the countries on this planet with over 200,000 cases. In about three months over 8,000 reported cases of death (Fig. 1b). Unfortunately, we still cannot see the end of this dark road, at least in the next couple of months.

We have managed to survive after other outbreaks:
MERS-CoV, ${ }^{1,2}$ SARS, ${ }^{3,4}$ Ebola, ${ }^{5}$ and of course the flu.

Fortunately, we have doctors, vaccinologists, chemists, nurses and many others fighting for us. ${ }^{6}$ Among them, there are American, Chinese, Indian, European, Japanese, Iranian, Korean..... There is no country boundary for the virus and there is no boundary for the scientists. Stay together, we will win; fight with each other, we will all lose.

Materials and manufacturing, not only play an important role in industry and research, ${ }^{7-9}$ but also play a critical role in this battle against the virus. Fig. 2 shows a typical structure for
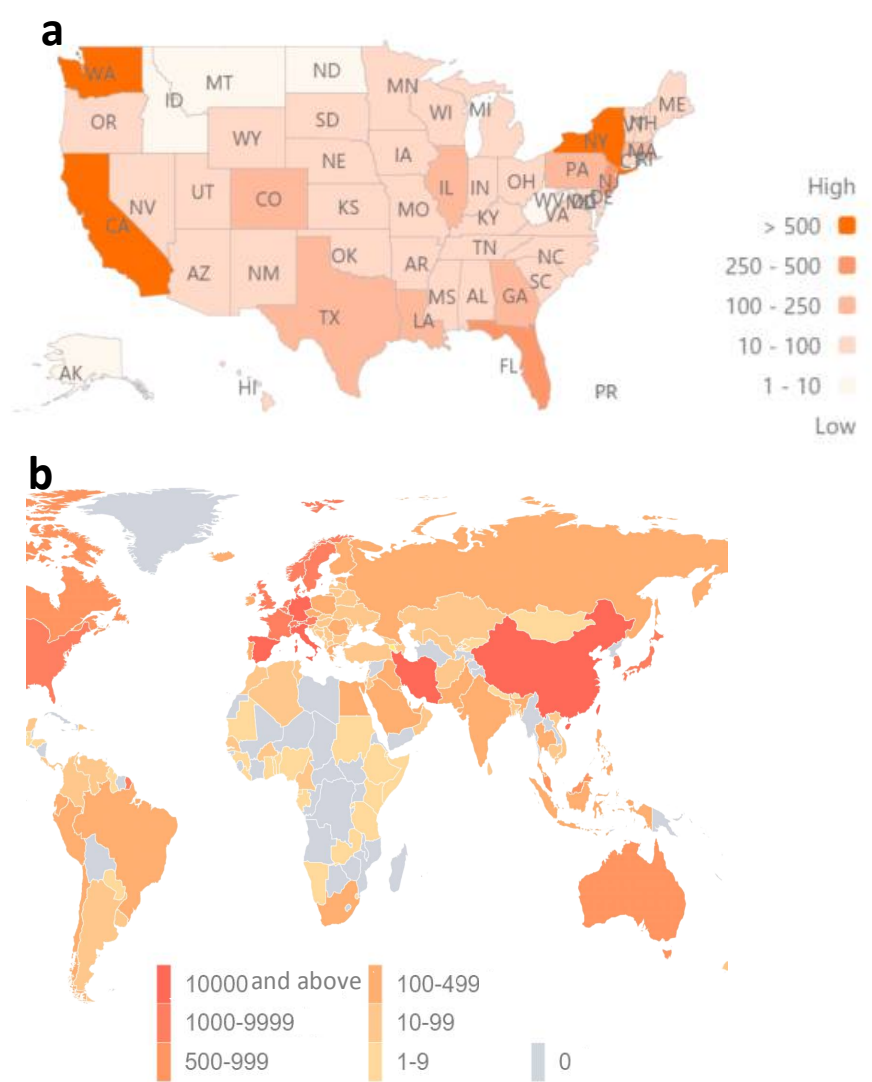

Fig. 1 a: Tthe COVID-19 in USA; b: The COVID-19 worldwide, by March $17^{\text {th }}, 2020$.

\footnotetext{
${ }^{I}$ Department of Chemistry and Physics, University of Arkansas, Pine Bluff, Arkansas 71601, USA

${ }^{2}$ School of Materials Engineering, Purdue University, West Lafayette, IN 47907, USA

*E-mail: luna@purdue.edu
} 
a medical mask used daily for nurses, doctors and everyone, especially in these special days. It does look simple; however, it's not simple when starting from crude oil. Fig. 3 shows a full process in order to make the mask. In order to get the polypropylene (Fig. 3c), the key material for medical mask and lots of other personal protection equipment, crude oil (Fig. 3a) needs to be refined in the refinery to get propylene. Chemists needs to synthesize the polypropylene from propylene first. Then, during the manufacturing procedure, polypropylene will be melt blown into non-woven fabric (Figs. 3(d\&e)) for medical mask. Electret processing is the key step during the manufacturing. Fig. 3e shows the process and the SEM (scanning electron microscope) image of the polypropylene fabric. The final step is the sterilization by ethylene oxide. It is worthy to note that the sterilization cannot be carried out by regular processes, such as UV light disinfection, which will destroy the polypropylene fiber and filtration.

At the end, I would like to end this Editorial with
"No one knows what we will face in the weeks ahead, but everyone knows enough to understand that COVID-19 will test our capacities to be kind and generous, and to see beyond ourselves ... May we all proceed with wisdom and grace." by Lawrence S. Bacow, the President of Harvard University.

\section{Acknowledgements}

We are grateful to U. S. Department of Education, Office of Postsecondary Education, Institutional Services (Title III, Part B, HBCU Program). Lu acknowledges the funding support from National Science Foundation NSF CMMI 1560834.

\section{References}

1. Z. A. Memish, A. Zumla, R. F. Alhakeem, A. Assiri, A. Turkestani, K. D. Al Harby, M. Alyemni, K. Dhafar, P. Gautret, M. Barbeschi, B. McCloskey, D. Heymann, A. A. Al Rabeeah and J. A. Al-Tawfiq. Hajj, Lancet, 2014, 383, 2073-2082.

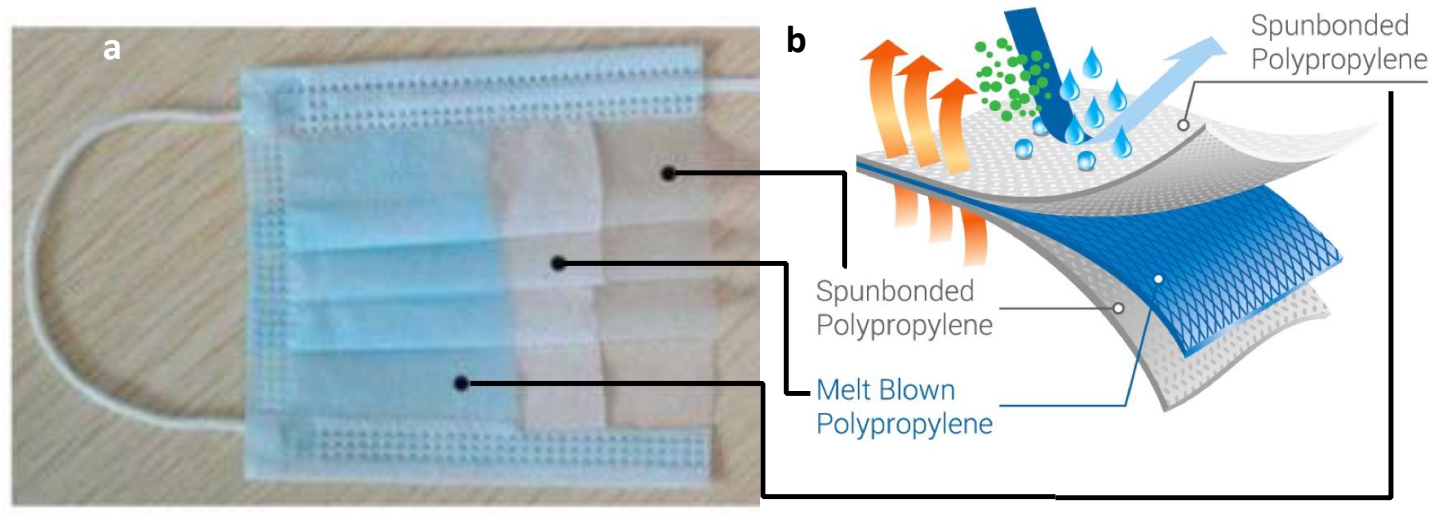

Fig. 2 Structure of a typical medical mask.

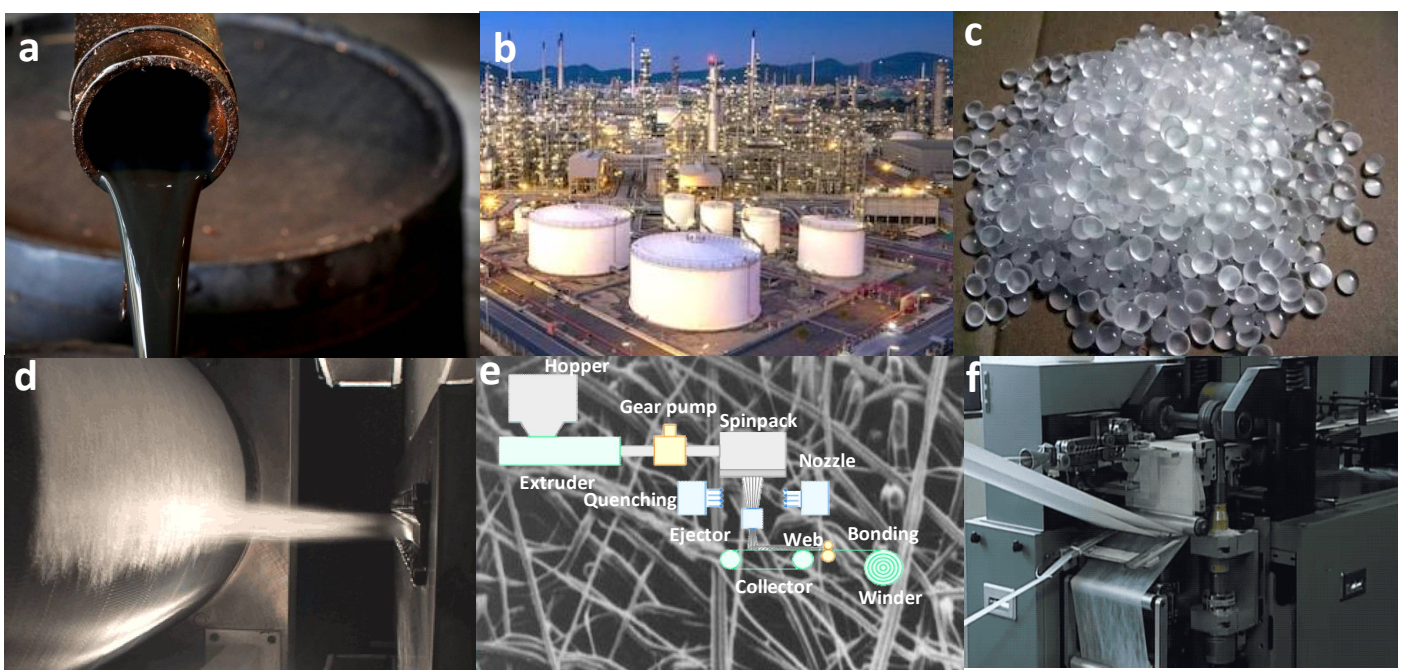

Fig. 3 a-c: From oil to polypropylene; d-f: Production of polypropylene fiber; e: Polypropylene fiber under SEM; f: From polypropylene fiber to material for medical mask. 
2. www.who.int/csr/don/31-october-2019-mers-the-unitedarab-emirates/zh/.

3. www.who.int/csr/sars/country/table2004_04_21/en/.

4. S. Perlman and A. A Dandekar, Nat. Rev. Immunol., 2005, 5, 917-927.

5. www.who.int/csr/disease/ebola/en/.

6. Q. Jiang, Z. Guo, G. Yang, E. Wujick and H. Gu, Eng. Sci., 2020, 9, 1-2.

7. J. Zhao, L.Wu, C. Zhang, B. Zeng, Y. Lv, Z. Li, Q. Jiang and Z. Guo, J. Mater. Chem. C, 2017, 5, 3903-3907.

8. F. Liu, G. Li, S. Luo, W. Li, Z. Huang, W. Li, F. Su, C. Li,
Z. Ding and Q. Jiang, ACS Appl. Mater. Interfaces, 2019, 11, 691-698.

9. Q. Jiang, X. K. Fu and Z. J. Chen, Chin. Chem. Lett., 2006, 17, 1447-1450.

10. Q. Jiang and T. Xu, Comment. Inorg. Chem., 2016, 36, 200-214.

Publisher's Note Engineered Science Publisher remains neutral with regard to jurisdictional claims in published maps and institutional affiliations. 